\title{
Residual stresses in large scale structures welded at low ambient temperatures
}

\author{
Jakob Klassen ${ }^{1, a^{*}}$, Thomas Nitschke-Pagel ${ }^{1, b}$ and Klaus Dilger ${ }^{1, c}$ \\ ${ }^{1}$ Langer Kamp 8, 38106 Braunschweig, Germany \\ aj.klassen@tu-braunschweig.de, bt.pagel@tu-braunschweig.de, 'k.dilger@tu-braunschweig.de,
}

\begin{abstract}
Keywords: Residual stresses, welding simulation, Sysweld, X-ray diffraction, low ambient temperature
\end{abstract}

\begin{abstract}
Prefabricated components during final assembling on site may be exposed to ambient temperatures below freezing point. Thus high cooling rates induce local hardening and can, however, affect distortion and residual stresses. These effects are investigated here for large-scale specimens in a climatic chamber simulating different possible ambient temperatures (down to $-10{ }^{\circ} \mathrm{C}$ ). Hereby experimentally obtained welding distortions and residual stresses are compared to numerical welding simulations.
\end{abstract}

\section{Introduction}

Design engineers of bigger constructions endeavour to prefabricate components as large as possible (or at least as large as transportation possibilities are) in a weld shop. Welding in a shop has the significant advantage of known and constant ambient conditions as, for instance, the ambient temperature. However, these ambient temperatures are rarely constant on a site, where the prefabricated components are joined together to the final assembly. Certainly, for assembly there are other climatic influences to be taken into account, such as precipitation and wind. In contrast to ambient temperatures, these influences can successfully be kept from the mounting area at low cost using encapsulations and thus are not considered in the following.

Manual metal active gas (MAG) welding is the most common joining technique for assembling on sites and therefore has been used in the presented work. Regardless of which process is used on the site one has to consider the influences of ambient temperature, as stated above. Low ambient temperature (even below freezing point), for instance, may influence the cooling time resulting from higher cooling rates, having an impact on phase transformations at low temperatures [1] as well as local hardening in general construction steels, resulting in complex residual stress states. The mechanical properties resulting from that may have a significant impact on the fatigue behaviour of cyclic loaded structures [2,3,4], examples for which are steel bridges. These constructions are in the focus of the presented work. The welding residual stresses, which were mentioned above, are hard to obtain on the site and therefore should be predicted or at least estimated in advance. One possible approach to close the gap of knowledge concerning welding residual stresses of multi-layer welds is the use of numerical welding simulations. There are a few commercially available software packages, one of which has shown its reliability of calculating welding residual stresses and distortions in the past, and therefore has been used in the presented work. The application of welding simulation software increased in the past decades, as new computer technologies lead to affordable computing power. Driven by that software engineers improved their product by means of user friendly interfaces, again leading to a broader number of users not only in the academic research area. Today numerous conferences and research works are carried out in this field.

The present paper is based on an ongoing research project welding of thick steel plates under site conditions. The focus of this research is on large-scale site connections of thick steel plates made of the fine grained construction steel grades, which have been derived from actual steel bridge constructions exactly as the investigated large scale components. All experiments on these 
components have been carried out in a climatic chamber simulating different ambient air temperatures down to $-10^{\circ} \mathrm{C}$. Although it would be technically possible to extend the investigations to $-60^{\circ} \mathrm{C}$, this limitation has been chosen since it corresponds to German health and safety regulations marking the lowest tolerable temperature for welding personnel on the site. Experienced welders manually produced each of the welds under circumstances most closely to reality accompanied by acquisition of all relevant data. The welding experiments were followed by residual stress determination using X-ray diffraction. All the experimentally obtained data has been used to build up numerical models for adjacent welding simulation. Concluding, the calculated and experimentally obtained results have been compared with each other with emphasis on welding residual stresses.

\section{Experimental procedure}

The investigated steel grades have been derived from the most common construction steel grades used for highly stressed welded bridge structures, namely the normalised rolled fine-grain structural steel P355NL2 with a minimum yield strength of $355 \mathrm{MPa}$ and in addition the P460NL with a minimum yield strength of $460 \mathrm{MPa}$. The special grade NL indicates a high resistance to brittle fracture and is predestined for the use at low temperatures.

All the welding has been conducted manually by experienced and construction site approved welders. The specimens (TD), which had to be joined in the climatic chamber, have been prefabricated in a weld shop under fair environmental conditions as it would have been done in reality. The prefabrication process included two-sided single layer fillet welds to join the $15 \mathrm{~mm}$ web plates to the $30 \mathrm{~mm}$ flanges, resulting in a standard I-beam. However, the focus of the presented work is on the resulting specimens (MS) arising from the mounting of two specimens (TD). The reason for choosing large scale components was to reduce or even avoid possible scale effects in the survey. The specimens' dimensions (compare Fig. 1) are limited in size only corresponding to the climatic chamber.
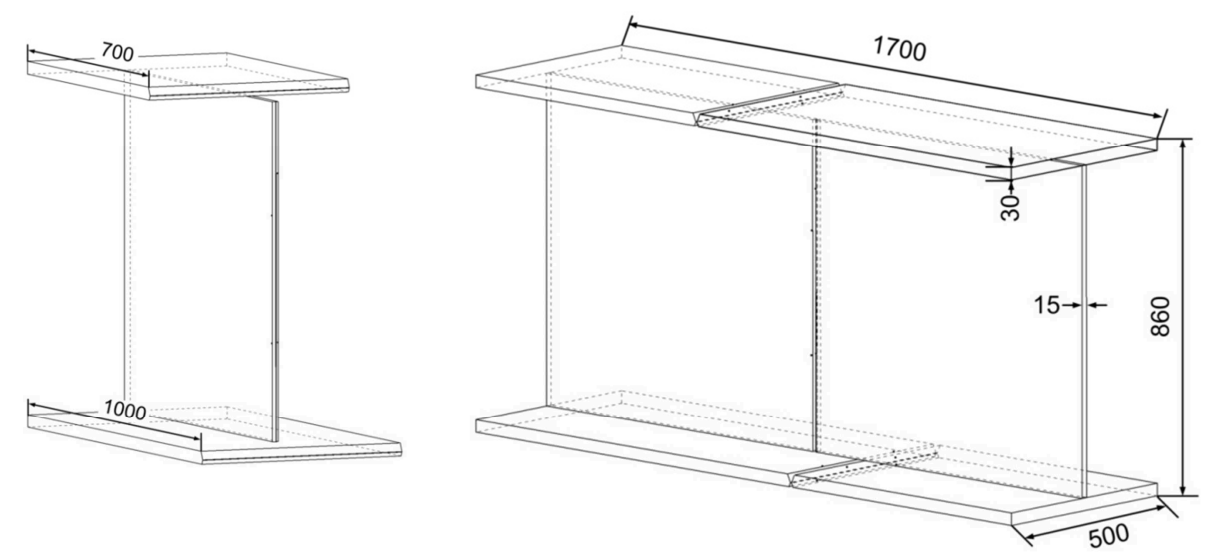

Fig. 1: Specimens dimensions [mm]; specimens TD (left) and MS (right)

During welding temperature profiles as well as distortions have been recorded. These data have been monitored to ensure normative references for preheating conditions and interpass temperatures and in addition have also been used to build up and validate the derived numerical models. Temperature profiles have been determined using type-K thermocouples. Subsequent to welding the near surface residual stresses have been calculated with the $\sin ^{2} \psi$-method (in accordance with [5]) from measured interference lines using X-ray diffraction with a $2 \mathrm{~mm}$ aperture on an $\Omega$ diffractometer (compare Fig. 2). 

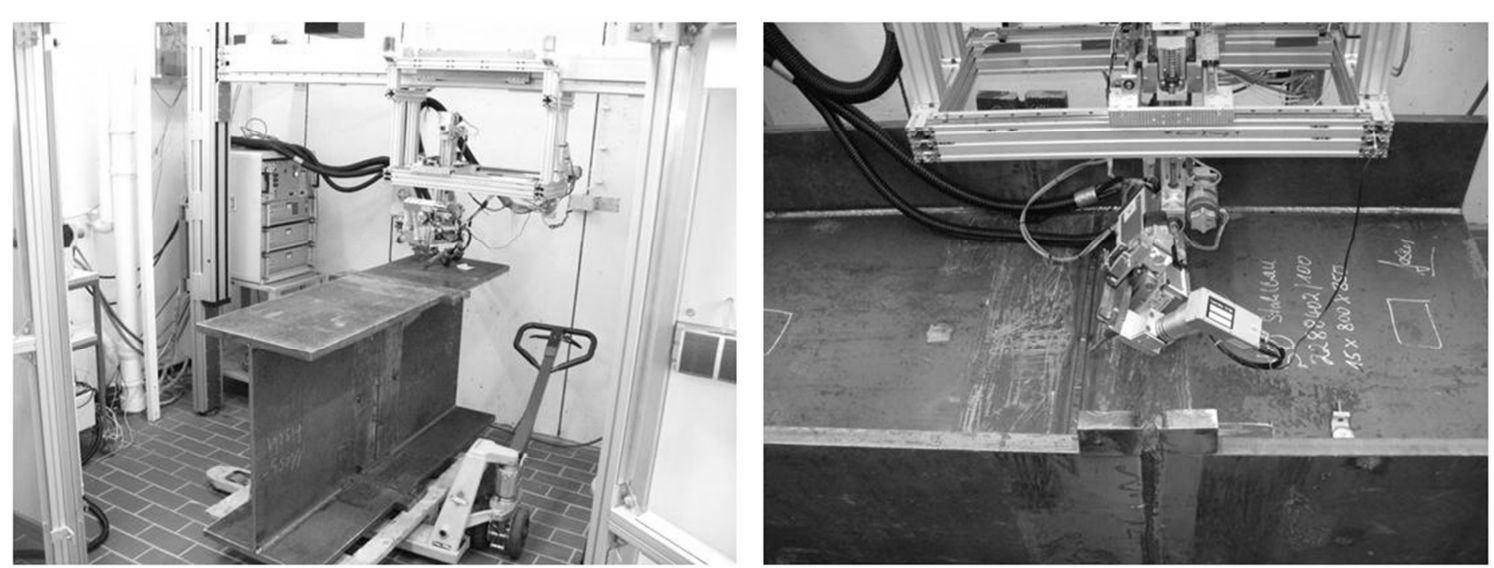

Fig. 2: Measuring booth for residual stress determination (left); diffractometer aimed at the specimens web seam (right)

\section{Numerical welding simulation}

Transient 3D simulations of temperature field and mechanics have been carried out with the software SYSWELD (version 2012), being a commercial finite element code which has shown good results in similar investigations in the past. Not only the temperature-dependent material properties are considered, but also phase transformations and the transformation plasticity including volumetric changes due to transformation. The preset elastic-plastic material with isotropic hardening remained unchanged. Modelling the specimens, simplifications had to be made, one of which is disregarded possible prior processing steps. The material is assumed to be geometrically free of imperfections. Furthermore the plates are assumed to be stress free, since the steel grades are normalized fine grain steels. The material data deposited in the used software do not take into account temperature dependent mechanical and thermal properties. The data set is bounded below to room temperature. Since welding has been carried out close to national standards, preheating of a rather large area was applied. Thus temperature dependent influences on the material behaviour at low temperatures, as vividly described in $[6,7]$, could be neglected.

Prior to calculate the first and rather simple TD specimens, comparative calculations with simplified models have been carried out, which justified the bisection of the TD model without a loss of information. The calculated temperature fields and deformations have reached good agreement with the experimentally obtained values, thus validating the heat sources and justifying its transformation to the larger MS specimen in the following steps (compare Fig. 3, left). These specimens as well have been modelled taken into account simplifying symmetry, thus reducing calculation times to a certain degree. The final model is shown on the right hand side in Fig. 3 .
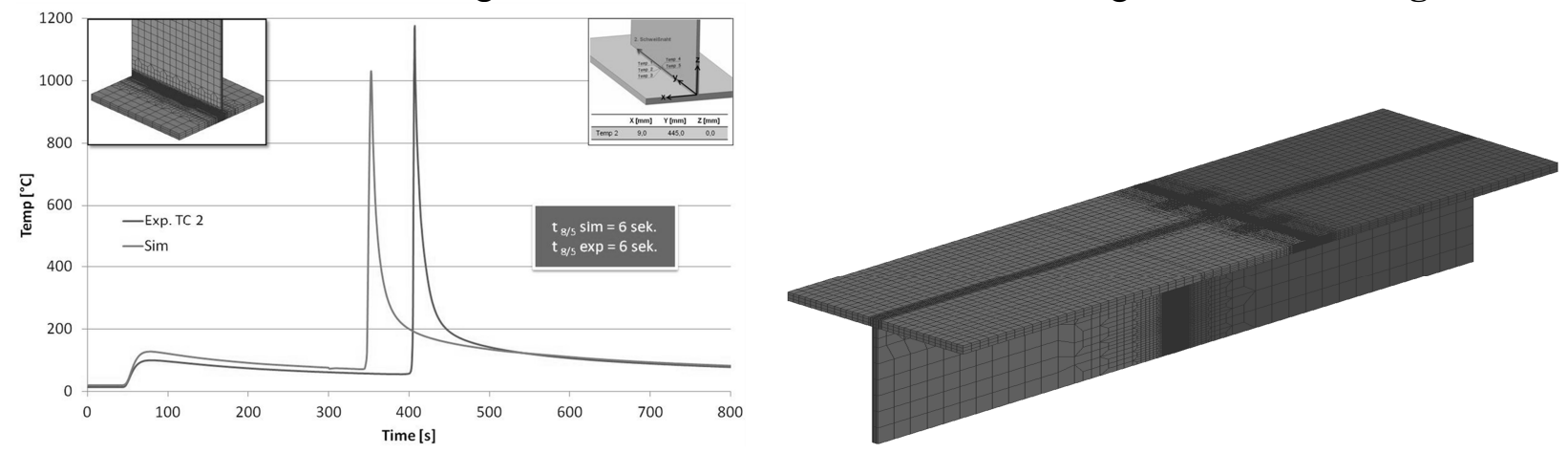

Fig. 3: (left) Validation of temperature fields for specimen TD; (right) Isometric view of the numerical model of specimen MS

But still calculation times have exceeded several weeks and therefore are of no use for industrial purposes, which lead to further simplifications relating to the actual weld build-up to keep computation time manageable. The numerical model, thus evolved, has been reduced in weld beads, 
from 23 single beads to 6 mayor layers, as shown in Fig. 4. These simplifications reduced calculation time to less than two weeks, which meant a reduction of over $70 \%$ in time.
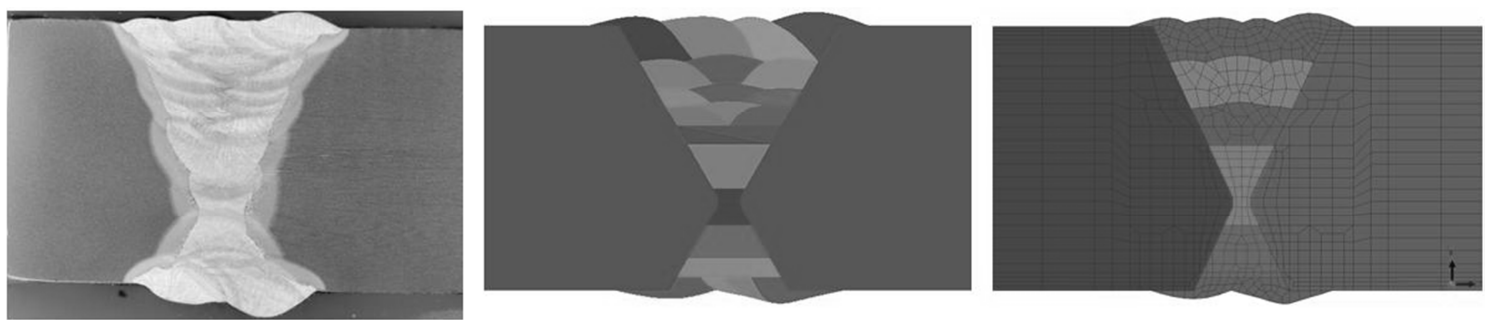

Fig. 4: $30 \mathrm{~mm}$ flange connection; macro section (left), derived weld build-up (centre), simplified numerical model (right)

\section{Results}

Only an extract of the result database is shown here with emphasis on residual stress comparison between experimentally obtained data and calculated values for a flange connection of the steel grade P355. Summarizing single weld beads to larger layers does not allow a meaningful comparison between the measured and calculated temperature fields, as it is often done for validating numerical models in welding simulation. Despite these circumstances, still relatively well-matching results were achieved for residual stresses, as can be seen in Fig. 5; comparison between the measured and calculated longitudinal residual stresses determined at $140 \mathrm{~mm}$ away from the beams edge (see description in lower right corner of the figure) in a site joint welded at room temperature. The calculations are in good agreement with the experiment. Both, the weld toe area as well as the descending course into the unaffected base material are in good agreement.

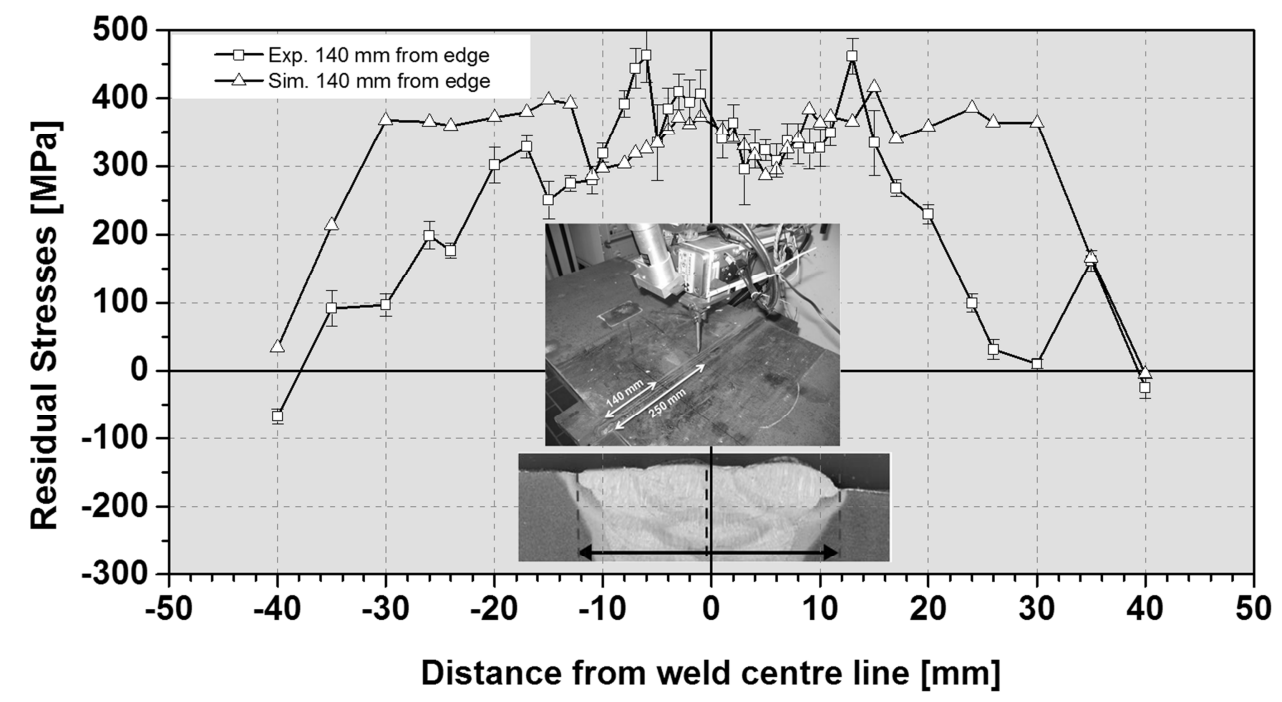

Fig. 5: Comparison of measured and calculated longitudinal residual stresses (upper flange, $140 \mathrm{~mm}$ from edge), each welded at RT.

As stated above, one of the most important points of this work is the influence of negative ambient temperatures on the welding residual stresses. In this respect it is noted that preheating (using heating mats) has been applied to meet national standards and the welding procedure specifications. Preheating, however, has attenuated the effect of different ambient temperatures. As can be seen in Fig. 6, temperature profiles, which have been recorded with thermocouples at comparable positions, show that cooling does almost not depend on the ambient temperature. Both, the peak temperatures and cooling curves as well as the t8/5-time are nearly the same. 


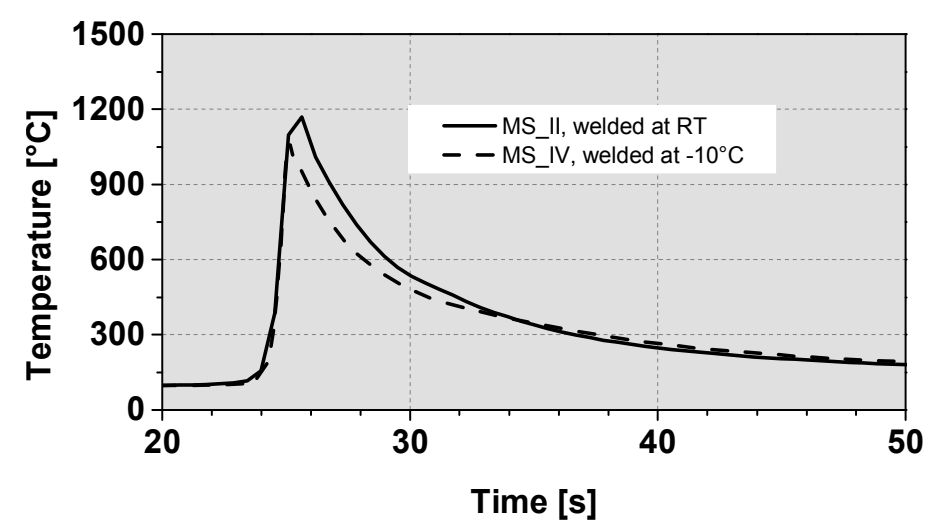

Fig. 6: Comparison of temperature profiles between MS II $\left(20^{\circ} \mathrm{C}\right)$ and $\operatorname{MS} \operatorname{IV}\left(-10^{\circ} \mathrm{C}\right)$

These results are confirmed by residual stress determinations. In Fig. 7 the longitudinal residual stresses are depicted. The only deviations arise from errors of measurement, which result from highly inhomogeneous surface texture, thus not being well suited for radiographic examinations, as described by the authors in [8].

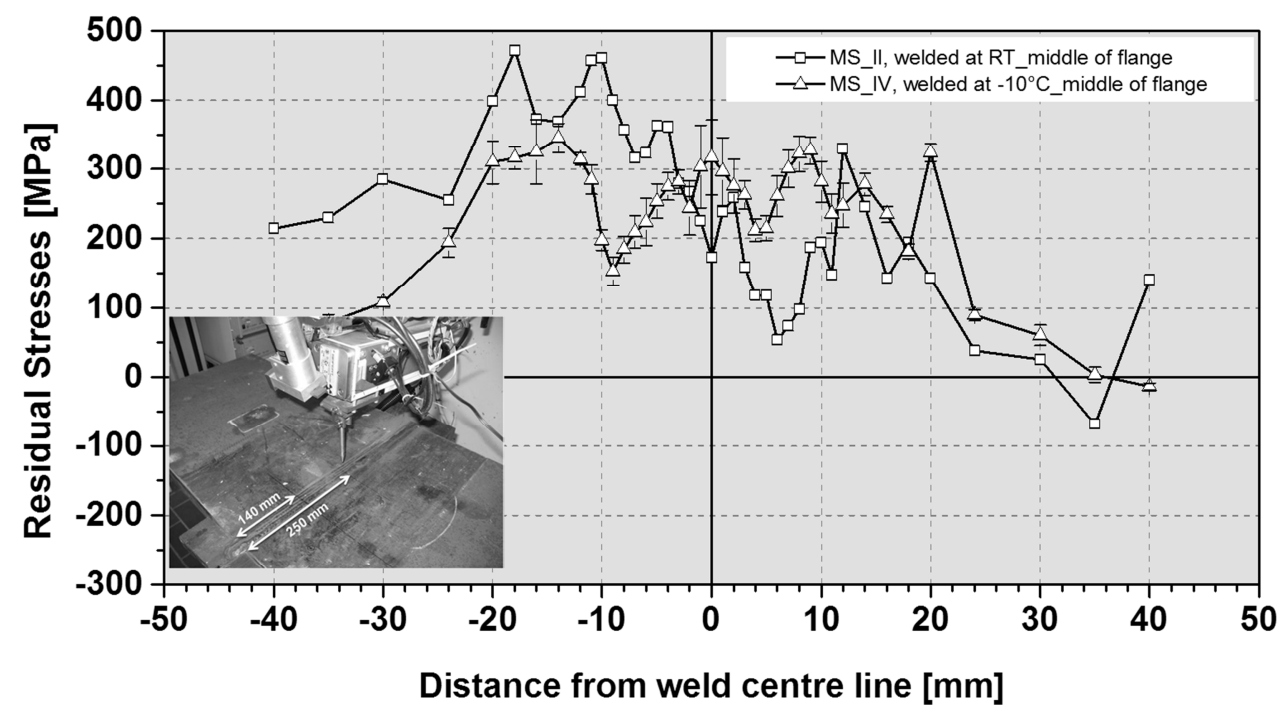

Fig. 7: Comparison of longitudinal residual stresses determined at each upper flange of MS II (welded at RT) and MS IV (welded at $-10{ }^{\circ} \mathrm{C}$ )

\section{Summary}

Site connections of two I-beams have been investigated under varying ambient temperatures, which experimentally have been simulated in a climatic chamber. An ambient temperature below $-10^{\circ} \mathrm{C}$ has not been investigated, since health and safety regulations for the welding personnel prohibit welding below that level. The investigated steel grades are mostly common structural steels for highly loaded structures like steel bridges. The welding experiments have been accompanied by measurements of welding induced temperature fields and distortions. Measurement data obtained from experiments have been used for numerical model validation.

The numerical welding simulation has been performed with SYSWELD. The calculated welding residual stresses have been compared to experimentally obtained data from X-ray diffraction. Although some simplifications have been made in the numerical models, still good results were achieved. The agreement between the calculated and measured residual stresses is exemplified in selected comparisons. Calculations have been performed not only for site connections welded at room temperature but also for different ambient temperatures. The comparisons of temperature 
fields as well as residual stresses of a site connection welded at room temperature and welded at $-10{ }^{\circ} \mathrm{C}$, however, show no significant influence of the initial ambient temperature.

It can be concluded that a temperature difference of some $30^{\circ} \mathrm{C}$ to the initial temperature has no significant effect on the cooling rates and thus on the resulting welding residual stresses of thickwalled components. Firstly, the welding components have been preheated to comparable temperature states, according to national welding standards. Secondly, the heat conduction within the components has a greater effect on the cooling than the heat losses due to convection. Although these findings are not surprising, they were confirmed experimentally for the first time. For small and medium-sized companies, which are often willing to perform welding at low or even negative temperatures, these results have a significant practical benefit.

\section{Acknowledgements}

We would like to thank the German Federation of Industrial Research Associations (AiF) for its financial support of the research project IGF-Nr. 16937N. This project was carried out under the auspices of AiF and financed within the budget of the Federal Ministry of Economics and Technology (BMWi) through the program to promote joint industrial research and development (IGF). Special thanks to the IMO Leipzig GmbH and Stahlbau Dessau GmbH \& Co. KG for carrying out the welding work and the preparation of welding procedures.

\section{References}

[1] Th. Nitschke-Pagel, K. Dilger, Eigenspannungen in Schweißverbindungen - Teil 1: Ursachen der Eigenspannungsentstehung beim Schweißen, in: Schweißen und Schneiden 58 (2006) 466-479.

[2] D. Radaj, M. Vormwaldt, Ermüdungsfestigkeit - Grundlagen für Ingenieure, 3. Auflage. Springer Verlag, 2007.

[3] Th. Nitschke-Pagel, Eigenspannungen und Schwingfestigkeit geschweißter Feinkornbaustähle. Dissertation TU Braunschweig, 1994.

[4] E. Macherauch, H. Wohlfahrt, Eigenspannungen und Ermüdung, in: Ermüdungsverhalten metallischer Werkstoffe, Deutsche Gesellschaft für Metallkunde e.V., Oberursel, (1985) 237/83.

[5] E. Macherauch, P. Müller, Das $\sin ^{2} \psi$-Verfahren der röntgenografischen Spannungsmessung, in: Zeitschrift für angewandte Physik, Band 13 (1961) 305-312.

[6] F. Hickel, Über die mechanischen Eigenschaften metallischer Werkstoffe bei tiefen Temperaturen, in: Werkstoffe und Korrosion, Heft 2, 1962.

[7] L. Kopp, Werkstoffverhalten unter mechanischer Beanspruchung bei hohen und tiefen Temperaturen, in: Chemie-Ing.-Techn. 42, 1970.

[8] J. Klassen, Th. Nitschke-Pagel, Influence of low ambient temperatures on the residual stress generation in fatigue-loaded GMA-welded structures, IIW Document XIII-2484-13, 2013. 